\title{
Inclusão de fibra alimentar em pães isentos de glúten
}

Inclusion of dietary fiber in gluten-free breads

\author{
Andressa Luciane Ceccon Saueressig ${ }^{1 *}$, Tiago André Kaminski², Thomas Duzac Escobar ${ }^{2}$ \\ 1 Universidade Federal do Pampa (UNIPAMPA), Curso de Nutrição, Campus Itaqui, Itaqui/RS - Brasil \\ 2 Universidade Federal do Pampa (UNIPAMPA), Departamento de Ciência e Tecnologia de Alimentos, Campus Itaqui, Itaqui/RS - Brasil
}

\section{*Corresponding Author}

Andressa Luciane Ceccon Saueressig, Universidade Federal do Pampa (UNIPAMPA), Curso de Nutrição, Campus Itaqui, Rua Luiz Joaquim de Sá Britto, s/n, Promorar, CEP: 97650-000, Itaqui/RS - Brasil, e-mail: andressasaueressig@hotmail.com

Cite as: Inclusion of dietary fiber in gluten-free breads. Braz. J. Food Technol., v. 19, e2014045, 2016.

Received: Aug. 11, 2014; Accepted: May 11, 2016

\section{Resumo}

Foram desenvolvidas quatro formulações de pães, isentos de glúten e com a inclusão de fibra alimentar solúvel e insolúvel, avaliando suas propriedades físicas, composição química, aceitação e intenção de compra do consumidor. O padrão (1) teve a farinha de arroz, fécula de mandioca, ovo, leite em pó, óleo de girassol, sal, açúcar, fermento biológico seco e água como ingredientes. Nos demais, a fécula foi parcialmente substituída por inulina (2), farelo de arroz desengordurado e inulina (3), e farelo de arroz desengordurado (4). A cor do pão 2 diferiu apenas na casca, que ficou menos vermelha e amarela que o 1. A inclusão do farelo de arroz proporcionou coloração mais escura, vermelha e amarela à crosta e miolo dos pães 3 e 4 . A perda de peso e rendimento variaram apenas em relação ao pão 2, que teve maior perda de peso e menor rendimento, provavelmente devido ao colapso da massa, que não foi capaz de manter a estrutura na fase de crescimento. O custo dos pães com inulina foi maior, pois este ingrediente é um reconhecido prebiótico, adquirido em estabelecimentos farmacêuticos; enquanto que o custo do pão apenas com farelo diminuiu, já que se trata de um subproduto industrial, obtido da extração do óleo de arroz. Na composição química, houve incremento nos teores de cinzas, proteínas e fibra alimentar, principalmente insolúvel, nos pães 3 e 4; enquanto que o pão 2 apresentou menor teor proteico e maior teor de fibra alimentar, principalmente solúvel. Nutricionalmente, admite-se incremento do valor nutricional em detrimento de carboidratos digeríveis e do valor calórico. Sensorialmente, os pães 3 e 4 tiveram menor aceitação nos atributos cor e sabor, mas não diferiram dos pães 1 e 2 nos atributos odor e textura, e na intenção de compra dos consumidores. Conclui-se que o consumo dos pães que tiveram substituição parcial da fécula é garantia de alimento com qualidade funcional, nutricional e sensorial, principalmente para celíacos.

Palavras-chave: Doença celíaca; Pão; Farinha de arroz; Farelo de arroz; Inulina.

\section{Summary}

Four gluten-free bread formulations were developed, with the inclusion of soluble and insoluble dietary fiber. Physical properties, chemical composition, acceptance and purchase intent of consumers were evaluated. The standard sample (1) had rice flour, cassava starch, egg, powdered milk, sunflower oil, salt, sugar, dry yeast and water as ingredients. In the other samples, the starch was partially replaced by inulin (2), defatted rice bran and inulin (3), and defatted rice bran (4). The color of bread 2 differed only in the crust, which was less red and yellow than standard sample (1). The inclusion of rice bran yielded a darker, red and yellow color to the crust and the crumb of the breads 3 and 4 . Only bread 2 had loss of weight and lower yield, compared to the other samples, probably due to the dough structure collapse, which was not sustained at the growth stage. The cost of the breads with inulin was greater, for this is a well known prebiotic ingredient, acquired in pharmaceutical establishments; whereas the cost of bread with bran decreased, since it is an industrial by-product obtained from the extraction of rice oil. Regarding chemical composition, there was an increase in ash, protein and dietary fiber contents, especially insoluble, in breads 3 and 4; whereas bread 2 had lower protein and higher dietary fiber content, especially soluble. Nutritionally, an increase in the nutritional value over digestible carbohydrates and caloric value is accepted. Sensorily, 
breads 3 and 4 were less preferred regarding color and flavor attributes, but did not differ from breads 1 and 2 in odor and texture attributes, and consumers purchase intent. It was concluded that the consumption of breads with partial replacement of starch ensures food functional quality, nutritional and sensorial, especially in the celiac case.

Keywords: Celiac disease; Bread; Rice flour; Rice bran; Inulin.

\section{Introdução}

O glúten é o complexo proteico insolúvel formado na etapa de mistura dos ingredientes da massa, mediante hidratação das proteínas do trigo (CAUVAIN; YONG, 2009). As proteínas do trigo formadoras de glúten são as glaiadinas, que proporcionam capacidade de expansão à massa, e as gluteninas, responsáveis pelas propriedades de elasticidade da massa (DEMIRKESEN et al., 2010).

Contudo, algumas pessoas apresentam manifestações de hipersensibilidade ao glúten, conhecida como doença celíaca, que é caracterizada pela inflamação do intestino delgado e pode levar a má absorção de nutrientes, devido ao dano causado às células epiteliais de absorção que envolvem o intestino (ORMENESE; CHANG, 2002), tendo como único tratamento a isenção de glúten na dieta (TORRES et al., 2009).

Além da restrição de diversos produtos de panificação na dieta, os celíacos encontram disponibilidade limitada, além da qualidade tecnológica e sensorial inferior, e preços mais elevados dos produtos isentos de glúten em relação aos de trigo (HERA et al., 2013; KOTZE, 2006). Embora a oferta de produtos tenha aumentado nos últimos anos, ganhando espaço nas prateleiras dos mercados e padarias, em determinadas regiões, como na Fronteira Oeste do Estado do Rio Grande do Sul, há escassez de produtos de panificação isentos de glúten que, quando disponíveis, são comercializados por preços ainda mais elevados. Em decorrência dos fatores anteriormente descritos, grande parte das preparações do cardápio do paciente celíaco é caseira, demandando tempo e dedicação (CÉSAR et al., 2006).

O desenvolvimento de produtos isentos de glúten, destinados aos celíacos, representa um desafio para a indústria de panificação, devido à dificuldade de reproduzir as características dos produtos com trigo, tanto em termos tecnológicos, como sensoriais e nutricionais (FIGUEIRA et al., 2011). Como o glúten é responsável pela estrutura dos produtos de panificação tradicionais, sua ausência pode resultar em produtos com textura de desintegração, de massa crua e líquida, com casca sem coloração característica, de pequena crosta, rápido processo de envelhecimento (endurecimento), sabor menos intenso, entre outros defeitos de qualidade (GALLAGHER et al., 2004).

Desta forma, a massa de pães sem glúten só poderá reter os gases se adicionada de ingredientes com esta função, tais como os hidrocoloides (GALLAGHER et al., 2004). Dentre os ingredientes utilizados em substituição ao trigo para produção de pães, a farinha de arroz tem se destacado, inicialmente por ser uma matéria-prima econômica e amplamente disponível, mas também por características como gosto suave, coloração branca, hipoalergenicidade, ausência de glúten e facilidade de digestão, fatores que a tornam um ingrediente atrativo para a substituição da farinha de trigo (CLERICI; EL-DASH, 2006; SOARES JÚNIOR et al., 2009).

Além da busca por substitutos do glúten com características tecnológicas e sensoriais semelhantes, há também a preocupação pelo enriquecimento nutricional de produtos para celíacos, pois a dieta destes, normalmente, é pobre em micronutrientes e componentes fisiologicamente importantes, como a fibra alimentar (WRONKOWSKA et al., 2008).

As fibras alimentares, solúveis e insolúveis, proporcionam diversos benefícios à saúde (SILVA et al., 2012), ao mesmo tempo que também atuam na manutenção das características tecnológicas e sensoriais (CAPRILES; ARÊAS, 2012). A inulina é um polissacarídeo composto por unidades de $\beta$-D-frutofuranosil unidas através de ligações $2 \rightarrow 1$, com grau de polimerização na faixa de 2 a 60 unidades e finalizada com uma unidade de sacarose na sua extremidade redutora; como não é hidrolisada por enzimas digestivas, mas fermentada no cólon, além de componente da fração solúvel da fibra alimentar, tem reconhecida atividade prebiótica (DAMODARAN et al., 2010). Já o farelo de arroz representa uma fonte de diversos nutrientes, tais como proteínas, lipídeos e fibras insolúveis, dentre elas estão principalmente hemicelulose e lignina (LACERDA et al., 2009). Embora amplamente utilizado na produção de rações para animais, o farelo de arroz também pode ser utilizado em produtos alimentícios, principalmente na forma desengordurada, na qual a rancificação é prevenida (SOARES JÚNIOR et al., 2009).

Neste contexto, o trabalho teve por objetivo desenvolver formulações de pães isentos de glúten e com a inclusão de fibras alimentares solúveis e insolúveis, avaliando suas propriedades físicas, composição química, aceitação e intenção de compra do consumidor.

\section{Material e métodos}

\subsection{Elaboração dos pães}

Em panificadora (Chrome, Philco), foram elaboradas quatro formulações de pães de forma no ciclo Ultrarrápido (1 hora acrescida de 10 minutos de assamento). O pão padrão (pão 1) apresentou farinha de arroz (Maninho ${ }^{\circledR}$, Comman), fécula de mandioca $\left(\right.$ Amafil $\left.^{\circledR}\right)$, ovo, leite em 
pó integral (Elegê), óleo de girassol (Salada, Bunge), sal refinado iodado $\left(\right.$ Cisne $\left.^{\circledR}\right)$, açúcar cristal (Santa Isabel), fermento biológico seco (Mauri) e água, como ingredientes. Nas demais formulações, $75 \%$ da fécula de mandioca foi substituída por inulina (Orafti® GR, Beneo) (pão 2); farelo de arroz desengordurado (cedido na forma de pellets pela empresa Camil Alimentos S.A., unidade de Itaqui/RS, moído em micromoinho e peneirado através de peneira com abertura de $300 \mu \mathrm{m}$ ) e inulina (pão 3); e farelo de arroz desengordurado (pão 4). Na Tabela 1, são apresentados as quantidades de cada ingrediente e os custos das formulações de pães, calculados a partir dos preços dos ingredientes adquiridos no comércio regional.

\subsection{Propriedades físicas}

Através de colorímetro (CR-400, Minolta) verificou-se três coordenadas de cromaticidade: $a^{*}, b^{*}$ e $L^{*}$, na casca e no miolo dos pães (GOMES et al., 2012).

A perda de peso no assamento foi avaliada pela fórmula: [(peso da massa crua - peso da massa cozida) $\times 100$ / peso da massa crua. O rendimento dos pães foi determinado pela razão entre o peso da massa assada pelo peso da massa crua. O volume final foi mensurado pelo método de deslocamento de sementes de painço (CAPRILES; ARÊAS, 2012).

\subsection{Composição química}

As análises de composição química foram precedidas pela pré-secagem dos pães em estufa com circulação de ar forçado (SL 102/480, Solab) a $60{ }^{\circ} \mathrm{C} / 24$ horas. Posteriormente, foi realizada a moagem em micromoinho (TE-650, Tecnal). As amostras moídas foram armazenadas em sacos de polietileno, identificadas, vedadas e congeladas $\mathrm{a}-18^{\circ} \mathrm{C}$ até a realização das análises.

Foram determinados os teores de umidade, cinzas, proteína bruta e fibra alimentar (insolúvel e solúvel) conforme os métodos analíticos propostos pela Association of Official Analytical Chemists (HORWITZ, 2000). O teor de lipídios foi quantificado a partir do método descrito por Bligh e Dyer (1959). A quantidade de carboidratos foi estimada pela diferença de 100 menos os parâmetros citados anteriormente.

\subsection{Análise sensorial}

Este estudo foi previamente submetido e aprovado pelo Comitê de Ética em Pesquisa com Seres Humanos da Universidade Federal do Pampa, mediante parecer de número 721.802. O teste foi realizado com 30 provadores, de ambos os sexos, não treinados, componentes da comunidade acadêmica da Universidade Federal do Pampa - campus Itaqui e que aderiram livremente à pesquisa mediante assinatura do Termo de Consentimento Livre e Esclarecido. As amostras foram oferecidas na forma de meia fatia de pão, uma por vez e de maneira aleatória, sendo também disponibilizada água mineral. No teste de aceitabilidade, foram avaliados os atributos de cor, odor, sabor e textura, a partir de escala hedônica de nove pontos, sendo 1 para "desgostei muitíssimo" e 9 para "gostei muitíssimo". Na mesma ficha de avaliação, os provadores também responderam ao questionário do teste de intenção de compra, a partir de uma escala hedônica de cinco pontos, sendo 1 para "certamente não compraria" e 5 para "certamente compraria".

\subsection{Análise dos resultados}

O experimento foi conduzido em delineamento inteiramente casualizado, com três repetições. Os dados foram submetidos à análise de variância e comparados pelo teste de Tukey em nível de $5 \%$ de significância em programa Statistical Package for Social Sciences (SPSS) 8.0 para Windows.

Tabela 1. Custos dos ingredientes e seus percentuais nas formulações dos pães (Itaqui/RS, 2013).

\begin{tabular}{|c|c|c|c|c|c|}
\hline \multirow{2}{*}{ Ingredientes } & \multirow{2}{*}{$\begin{array}{l}\text { Custo } \\
\text { (R\$/kg) }\end{array}$} & \multirow{2}{*}{\multicolumn{4}{|c|}{$\%$}} \\
\hline & & & & & \\
\hline Farinha de arroz & 7,00 & 80 & 80 & 80 & 80 \\
\hline Fécula de mandioca & 8,50 & 20 & 5 & 5 & 5 \\
\hline Inulina & 180,00 & 0 & 15 & 10 & 0 \\
\hline Farelo de arroz & 0,35 & 0 & 0 & 5 & 15 \\
\hline Ovo & 4,95 & 25 & 25 & 25 & 25 \\
\hline Sal & 2,30 & 2 & 2 & 2 & 2 \\
\hline Açúcar & 3,79 & 5 & 5 & 5 & 5 \\
\hline Fermento biológico & 15,84 & 3 & 3 & 3 & 3 \\
\hline Leite em pó & 18,75 & 4 & 4 & 4 & 4 \\
\hline Óleo de girassol & 4,90 & 7 & 7 & 7 & 7 \\
\hline Água & nd* & 60 & 60 & 60 & 60 \\
\hline Custo para $500 \mathrm{~g}$ das farinhas $(\mathrm{R} \$)$ & & 5,17 & 18,03 & 13,54 & 4,56 \\
\hline
\end{tabular}

$\mathrm{nd}^{*}=$ não determinado. 


\section{Resultados e discussão}

\subsection{Propriedades físicas}

Na Tabela 2, estão demonstrados os resultados da análise de cor das formulações de pães, demonstrando diferenças significativas, tanto na coloração da crosta como do miolo.

A substituição da fécula por inulina não alterou a luminosidade da casca e miolo dos pães, nem os atributos de cor $a^{*}$ e b* do miolo; no entanto, a casca deste pão (2) mostrou-se significativamente menos vermelha e amarela que do pão padrão (1). Já a inclusão do farelo de arroz proporcionou coloração significativamente mais escura, vermelha e amarela à crosta e miolo dos pães. Estas alterações foram proporcionais à quantidade de farelo adicionado, sendo maior na formulação de pão 4. Gomes et al. (2012) também demonstraram que, quanto maior o conteúdo de farelo de arroz, mais escuro e mais avermelhado se tornam as preparações.

Outras propriedades físicas, relacionadas ao peso, volume e rendimento dos pães, estão apresentadas na Tabela 3.

A perda de peso no assamento e o rendimento do pão 1 foram de 5,02\% e 0,95, respectivamente, e não variaram significativamente para os pães 3 e 4 . No entanto, o pão 2, que teve substituição de fécula por inulina, demonstrou perda de peso e rendimento respectivamente de 8,03\% e 0,92, significativamente distintos das demais formulações. Estes resultados estão provavelmente associados ao colapso da estrutura da massa no início do assamento do pão 2, que não foi capaz de manter a estrutura adquirida na fase de crescimento do pão (Figura 1).

O volume das formulações testadas não variou significativamente, demonstrando que os substitutos da fécula, inulina e farelo de arroz, não prejudicaram a manutenção da estrutura dos produtos (Tabela 3). Capriles e Arêas (2012) relataram que a inclusão de inulina, em diferentes proporções na preparação de pães isentos de glúten, proporcionou melhorias na estrutura e no volume dos pães. Provavelmente, o já relatado colapso da massa não proporcionou uma constatação de maior volume nos pães com inulina, pois a estrutura do pão era aparentemente maior na fase de crescimento, mas não era mantida no assamento (Figura 1). Ajustes de ingredientes, como o uso de menor quantidade de água e manutenção da quantidade de fécula, poderiam auxiliar a contornar estes problemas funcionais.

O cálculo do custo de cada formulação a partir dos custos dos ingredientes, demonstrados na Tabela 1, atribui o valor de $\mathrm{R} \$ 5,17$ para o pão padrão (1), este valor é mais do que triplicado $(R \$ 18,03)$ com a inclusão da inulina (2), enquanto diminui um pouco $(\mathrm{R} \$ 4,56)$ com farelo de arroz (4). O maior custo dos pães com inulina está relacionado ao fato de este ser um reconhecido prebiótico, adquirido em estabelecimentos farmacêuticos. Já o menor preço do pão apenas com farelo de arroz deve-se ao farelo ser um subproduto industrial de baixo custo, obtido durante a extração do óleo de arroz e ainda com pouca utilização na indústria alimentícia.

\subsection{Composição química}

$\mathrm{Na}$ Tabela 4, estão demonstrados os resultados da composição química das formulações.

Observa-se que a umidade variou significativamente, sendo maior nos pães com substituição da fécula por farelo de arroz (3 e 4) e menor no pão substituído por inulina (2). Isto deve estar associado às características das diferentes frações de fibra alimentar, com maior retenção de água pelas fibras insolúveis do farelo de arroz do que pela

Tabela 2. Atributos de cor das formulações de pães (Itaqui/RS, 2013).

\begin{tabular}{cccccc} 
& Atributo de cor & Pão 1 & Pão 2 & Pão 3 & Pão 4 \\
\multirow{4}{*}{ Casca } & $L^{*}$ & $72,78 \pm 1,24^{a}$ & $73,45 \pm 2,10^{a}$ & $71,46 \pm 0,68^{a}$ & $56,60 \pm 0,45^{b}$ \\
& $a^{*}$ & $-4,96 \pm 0,22^{c}$ & $-6,62 \pm 0,26^{d}$ & $-2,91 \pm 0,07^{b}$ & $1,42 \pm 0,20^{a}$ \\
\multirow{3}{*}{ Miolo } & $b^{*}$ & $28,11 \pm 0,60^{b}$ & $26,92 \pm 0,49^{c}$ & $28,62 \pm 0,33^{b}$ & $31,86 \pm 0,27^{a}$ \\
& $L^{*}$ & $69,11 \pm 1,09^{a}$ & $71,29 \pm 1,89^{a}$ & $62,43 \pm 0,25^{b}$ & $60,02 \pm 0,29^{b}$ \\
& $a^{*}$ & $-6,14 \pm 0,06^{c}$ & $-6,58 \pm 0,18^{c}$ & $-3,65 \pm 0,27^{b}$ & $-1,22 \pm 0,18^{a}$ \\
\hline
\end{tabular}

Valores expressos como média \pm desvio padrão seguidos por letras que indicam diferença estatística significativa nas linhas, em nível de $5 \%$ de significância pelo teste de Tukey.

Tabela 3. Rendimento e volume dos pães (Itaqui/RS, 2013).

\begin{tabular}{lcccc}
\multicolumn{1}{c}{ Parâmetro } & Pão 1 & Pão 2 & Pão 3 & Pão 4 \\
Perda de peso $(\%)$ & $5,02 \pm 0,54^{\mathrm{b}}$ & $8,03 \pm 0,49^{\mathrm{a}}$ & $5,30 \pm 1,40^{\mathrm{b}}$ & $5,62 \pm 0,57^{\mathrm{b}}$ \\
Rendimento em peso & $0,95 \pm 0,00^{\mathrm{a}}$ & $0,92 \pm 0,00^{\mathrm{b}}$ & $0,95 \pm 0,01^{\mathrm{a}}$ & $0,94 \pm 0,00^{\mathrm{a}}$ \\
Volume final $(\mathrm{mL})$ & $2000,00 \pm 100,00^{\text {ns }}$ & $2033,33 \pm 57,74^{\text {ns }}$ & $1933,33 \pm 57,74^{\mathrm{ns}}$ & $1866,67 \pm 57,74^{\mathrm{ns}}$ \\
\hline
\end{tabular}

Valores expressos como média \pm desvio padrão seguidos por letras que indicam diferença estatística significativa ou não significativa (ns) nas linhas, em nível de 5\% de significância pelo teste de Tukey. 


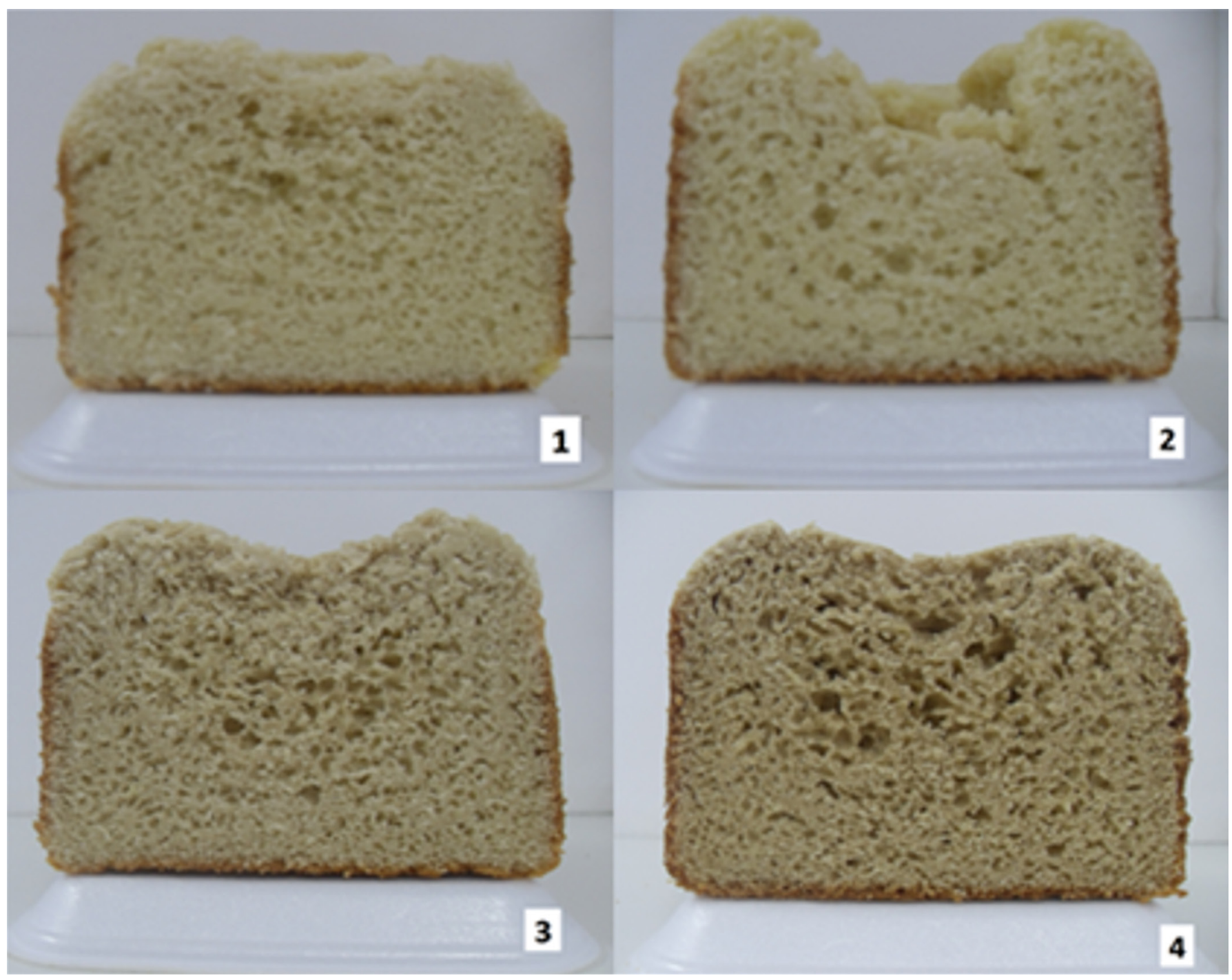

Figura 1. Aspecto das formulações de pães (Itaqui/RS, 2013). Legenda: 1 (pão padrão), 2 (pão com inulina), 3 (pão com inulina e farelo de arroz) e 4 (pão com farelo de arroz).

Tabela 4. Composição centesimal e valor calórico das formulações de pães sem glúten (Itaqui/RS, 2013)

\begin{tabular}{lrrrr}
\multicolumn{1}{c}{ Componente (\%) } & Pão 1 & Pão 2 & Pão 3 & Pão 4 \\
Umidade & $42,78 \pm 0,06^{\mathrm{c}}$ & $42,49 \pm 0,08^{\mathrm{d}}$ & $44,12 \pm 0,11^{\mathrm{b}}$ & $44,33 \pm 0,04^{\mathrm{a}}$ \\
Matéria mineral & $1,00 \pm 0,01^{\mathrm{c}}$ & $0,95 \pm 0,03^{\mathrm{c}}$ & $1,36 \pm 0,03^{\mathrm{b}}$ & $1,95 \pm 0,04^{\mathrm{a}}$ \\
Lipídios & $3,80 \pm 0,49^{\text {ns }}$ & $3,52 \pm 0,48^{\text {ns }}$ & $3,02 \pm 0,44^{\text {ns }}$ & $2,79 \pm 0,47^{\text {ns }}$ \\
Proteínas & $6,82 \pm 0,09^{\mathrm{b}}$ & $6,43 \pm 0,13^{\mathrm{c}}$ & $6,94 \pm 0,11^{\mathrm{b}}$ & $8,38 \pm 0,09^{\mathrm{a}}$ \\
Fibra alimentar & $1,70 \pm 0,11^{\mathrm{d}}$ & $4,25 \pm 0,10^{\mathrm{b}}$ & $3,41 \pm 0,13^{\mathrm{c}}$ & $4,88 \pm 0,29^{\mathrm{a}}$ \\
Insolúvel & $1,05 \pm 0,10^{\mathrm{c}}$ & $1,04 \pm 0,10^{\mathrm{c}}$ & $1,74 \pm 0,09^{\mathrm{b}}$ & $4,24 \pm 0,37^{\mathrm{a}}$ \\
Solúvel & $0,64 \pm 0,01^{\mathrm{c}}$ & $3,22 \pm 0,16^{\mathrm{a}}$ & $1,66 \pm 0,07^{\mathrm{b}}$ & $0,64 \pm 0,10^{\mathrm{c}}$ \\
Carboidratos & $43,90 \pm 0,69^{\mathrm{a}}$ & $42,36 \pm 0,37^{\mathrm{b}}$ & $41,16 \pm 0,52^{\mathrm{b}}$ & $37,67 \pm 0,58^{\mathrm{c}}$ \\
Valor calórico (Kcal) & $237,13 \pm 1,88^{\mathrm{a}}$ & $226,82 \pm 2,59^{\mathrm{b}}$ & $219,53 \pm 2,09^{\mathrm{c}}$ & $209,32 \pm 2,06^{\mathrm{d}}$ \\
\hline Valores
\end{tabular}

Valores expressos como média \pm desvio padrão seguidos por letras que indicam diferença estatística significativa ou não significativa (ns) nas linhas, em nível de $5 \%$ pelo teste de Tukey.

inulina. Este resultado também pode estar relacionado ao colapso da massa ocorrido no assamento do pão 2, que provavelmente proporcionou maior perda de água na forma de vapor.
Observa-se que os teores de matéria mineral foram significativamente maiores nos pães com adição de farelo de arroz, com valores médios de 1,36\% e 1,95\% para os pães 3 e 4, respectivamente. Em preparações com 
adição de farelo de arroz é comum encontrar elevações relacionadas à matéria mineral, devido a sua elevada quantidade de fósforo, potássio, magnésio e cálcio em sua composição (BARBOSA et al., 2006).

Os teores de lipídios não diferiram significativamente entre as formulações, provavelmente porque o ingrediente substituído (fécula) apresentava teor lipídico semelhante ao da inulina e do farelo de arroz desengordurado.

O teor proteico do pão 2 foi significativamente inferior aos demais pães, com média de 6,43\%; enquanto que a média do pão 4, 8,38\%, foi a maior; os pães 1 e 3 apresentaram teores intermediários, 6,82\% e $6,94 \%$, respectivamente, sem diferença significativa entre si. Nota-se que a substituição de fécula por farelo de arroz, proporcionou maior teor proteico, que está relacionado ao considerável teor proteico contido no farelo de arroz. Chaud et al. (2009) verificaram o potencial da composição do farelo de arroz para possível utilização em alimentos e descreveram que este possui cerca de 15\% de proteína bruta em sua constituição.

Com relação à quantidade de fibras, percebe-se que a substituição de fécula proporcionou aumento significativo nos teores de fibra alimentar. A inclusão de inulina nos pães 2 e 3 conferiu aumento nos teores de fibra solúvel para 3,22\% e 1,66\%, respectivamente. Já a inclusão de farelo de arroz atribuiu maiores teores de fibra insolúvel nos pães 3 e 4, que tiveram médias de 1,74\% e 4,24\%, respectivamente. Desta forma, os pães 2, 3 e 4 poderiam ser rotulados como "fonte de fibras", pois apresentaram teores superiores a 3\%, definido como limite inferior pela RDC n 18 da Agência Nacional de Vigilância Sanitária (BRASIL, 1999).

As fibras alimentares, solúveis e insolúveis, proporcionam benefícios ao trato gastrointestinal desde sua ingestão até sua excreção, que refletem no combate a doenças cardiovasculares e do cólon, como constipação, diarreia e câncer de colo-retal (SILVA et al., 2012). As fibras solúveis possuem a capacidade de formar géis; assim, durante a digestão, formam uma massa gelatinosa que aumenta o conteúdo do estômago, atrasando o esvaziamento gástrico, proporcionando maior volume e lubrificação fecal, e reduzindo os níveis de colesterol plasmático (COZZOLINO, 2012; SILVA et al., 2012). As fibras insolúveis proporcionam o aumento do volume fecal, diminuindo o tempo de trânsito intestinal, aumentando a sensação de saciedade do organismo, reduzindo o tempo de absorção da glicose e promovendo a eliminação de resíduos que se alojam na parede intestinal (LACERDA et al., 2010; SILVA et al., 2012).

Lacerda et al. (2009), ao avaliarem a qualidade de biscoitos elaborados com farelo de arroz extrusado em substituição à farinha de trigo e fécula de mandioca, também constataram teores significativamente maiores para cinzas, proteínas e fibras insolúveis.

Os acréscimos nos teores de cinzas, proteínas e fibras nas formulações que tiveram a fécula de mandioca parcialmente substituída foram abatidos no conteúdo de carboidratos digeríveis. Este componente ficou com valor médio de 43,90\% no pão 1, significativamente superior ao dos pães 2, 3 e 4, que apresentaram valores médios de $42,36 \% ; 41,16 \%$ e $37,67 \%$, respectivamente. Isto também refletiu no valor calórico das formulações, que reduziram de 237,14 kcal no pão 1 para 237,13; 226,82 e 209,32 kcal nos pães, 2, 3 e 4, respectivamente.

\subsection{Análise sensorial}

Na Tabela 5, estão expostos os resultados dos pães para cada atributo avaliado no teste de aceitabilidade e no teste de intenção de compra.

Todos os pães foram sensorialmente bem aceitos pelos provadores, com médias sempre superiores a 5 . Os provadores demonstraram maior aceitação pelos pães 1 e 2 no atributo cor e pelo pão 2, em comparação com o pão 4, no atributo sabor. Tais diferenças demonstram que pães mais claros e sem o característico sabor do farelo de arroz foram mais aceitos pelos consumidores. Em relação aos atributos odor e textura, os provadores tiveram a mesma aceitação pelos pães.

Alguns trabalhos já haviam constatado que, quanto maior a adição de farelo de arroz nas preparações, menor é a aceitação. Soares Júnior et al. (2009) verificaram que a adição de até 7,5\% de farelo de arroz em pães e biscoitos oferece boa aceitação do consumidor, mas, quando a adição ultrapassa esta porcentagem, a aceitação diminui em relação à coloração escura ocasionada pela inclusão de farelo de arroz na preparação. Capriles e Arêas (2012)

Tabela 5. Análise sensorial das formulações de pães isentos de glúten (Itaqui/RS, 2013).

\begin{tabular}{lllll}
\multicolumn{1}{c}{ Teste de Aceitabilidade } & Pão 1 & Pão 2 & Pão 3 & Pão 4 \\
Cor & $7,50 \pm 1,07^{\mathrm{a}}$ & $7,60 \pm 1,40^{\mathrm{a}}$ & $5,73 \pm 1,89^{\mathrm{b}}$ & $5,70 \pm 1,98^{\mathrm{b}}$ \\
Odor & $6,53 \pm 1,55^{\text {ns }}$ & $6,60 \pm 1,48^{\text {ns }}$ & $6,17 \pm 1,78^{\text {ns }}$ & $5,57 \pm 2,01^{\text {ns }}$ \\
Sabor & $6,13 \pm 1,64^{\mathrm{ab}}$ & $7,10 \pm 1,35^{\mathrm{a}}$ & $6,13 \pm 1,70^{\mathrm{ab}}$ & $5,63 \pm 2,14^{\mathrm{b}}$ \\
Textura & $5,93 \pm 1,64^{\text {ns }}$ & $6,53 \pm 1,48^{\text {ns }}$ & $6,33 \pm 1,79^{\text {ns }}$ & $6,27 \pm 1,98^{\text {ns }}$ \\
Teste de Intenção de compra & $3,23 \pm 0,97^{\text {ns }}$ & $3,77 \pm 1,10^{\text {ns }}$ & $3,13 \pm 1,07^{\text {ns }}$ & $3,17 \pm 1,26^{\text {ns }}$ \\
\hline
\end{tabular}

Valores expressos como média \pm desvio padrão seguidos por letras que indicam diferença estatística significativa ou não significativa (ns) nas colunas, em nível de 5\% pelo teste de Tukey. 


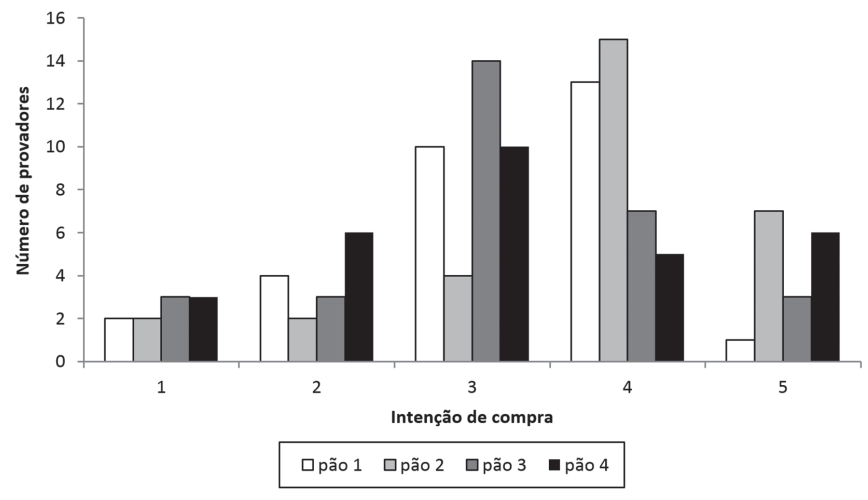

Figura 2. Pontuações atribuídas pelos provadores no teste de intenção de compra dos pães (Itaqui/RS, 2013). Legenda: pão 1 (padrão), pão 2 (com inulina), pão 3 (com inulina e farelo de arroz) e pão 4 (com farelo de arroz).

constataram que a adição de inulina melhorou a estrutura de pães sem glúten, consequentemente aumentando sua aceitabilidade nos atributos de sabor, textura e aparência.

Em relação à intenção de compra, não houve diferença significativa nas intenções declaradas pelos consumidores dos diferentes pães. Embora sem diferença significativa, a Figura 2 demonstra que as respostas dos consumidores quanto à intenção de compra dos pães, de modo geral, concentraram-se nas notas 3 e 4, ou seja, "talvez compraria" e "provavelmente compraria", respectivamente.

\section{Conclusão}

A substituição de fécula por inulina e farelo de arroz desengordurado em pães isentos de glúten alterou as propriedades físicas relacionadas à cor e ao peso dos produtos. Nutricionalmente, admite-se incremento do valor nutricional devido a aumento dos teores de matéria mineral, proteína e fibra alimentar, em detrimento de carboidratos digeríveis e do valor calórico. Sensorialmente, os pães acrescidos de farelo tiveram menor aceitação nos atributos cor e sabor, mas foram equivalentes ao pão padrão e apenas com inulina nos atributos odor e textura, além da intenção de compra pelos consumidores.

Conclui-se que o consumo dos pães de forma que tiveram substituição parcial da fécula é garantia de alimento com qualidade funcional, nutricional e sensorial, principalmente tratando-se da população celíaca, que possui inúmeras restrições na alimentação e, muitas vezes, uma dieta deficiente em micronutrientes e fibras.

\section{Referências}

BARBOSA, C. O.; LOPES, I. B. M.; MORANGO, M. A.; ARAÚJO, M. A. M.; MOREIRA-ARAÚJO, R. S. R. Conteúdo de minerais dos ingredientes e da multimistura. Ciência e Tecnologia de Alimentos, Campinas, v. 26, n. 4, p. 916-920, 2006. http://dx. doi. org/10.1590/S0101-20612006000400031.
BLIGH, E. C.; DYER, W. J. A rapid method of total lipid extraction and purification. Canadian Journal of Biochemistry and Physiology, Ottawa, v. 37, n. 8, p. 911-917, 1959. http://dx.doi. org/10.1139/059-099. PMid:13671378.

BRASIL. Agência Nacional de Vigilância Sanitária. Resolução $n^{\circ} 18$, de 30 de abril de 1999. Diretrizes básicas para análise e comprovação de propriedades funcionais e ou de saúde em rotulagens de alimentos. Diário Oficial [da] República Federativa do Brasil, Brasília, DF, 03 maio 1999.

CAPRILES, V. D.; ARÊAS, J. A. G. Effects of prebiotic inulin-type fructans on structure, quality, sensory acceptance and glycemic response of gluten-free breads. Food \& Function, London, v. 4, n. 1, p. 104-110, 2012. http://dx.doi.org/10.1039/C2FO10283H. PMid:23032642

CAUVAIN, S. P.; YOUNG, L. S. Tecnologia da panificação. 2. ed. Barueri: Manole, 2009. 440 p.

CÉSAR, A. S.; GOMES, J. C.; STALIANO, C. D.; FANNI, M. L.; BORGES, M. C. Elaboração de pão sem glúten. Revista Ceres, Viçosa, v. 53, n. 306, p. 150-155, 2006.

CHAUd, L. C. S.; ARRUdA, P. V.; FELIPE, M. G. A. Potencial do farelo de arroz para utilização em bioprocessos. Nucleus, Lorena, v. 6, n. 2, p. 33-46, 2009.

CLERICI, M. T. P. S.; EL-DASH, A. A. Farinha extrusada de arroz como substituto de glúten na produção de pão de arroz. Archivos Latinoamericanos de Nutrición, Caracas, v. 56, n. 3, p. 288-294, 2006.

COZZOLINO, S. M. F. Biodisponibilidade de nutrientes. 4. ed. Barueri: Manole, 2012. 1368 p.

DAMODARAN, S.; PARKIN, K. L.; FENNEMA, O. R. Química de alimentos de Fennema. 4. ed. Porto Alegre: Armed, 2010. 900 p.

DEMIRKESEN, L.; MERT, B.; SUMNU, G.; SAHIN, S. Rheological properties of gluten-free bread formulations. Journal of Food Engineering, Essex, v. 96, n. 2, p. 295-303, 2010. http://dx.doi. org/10.1016/j.jfoodeng.2009.08.004.

FIGUEIRA, F. S.; CRIZEL, T. M.; SILVA, C. R.; SALAS-MELLADO, M. M. Pão sem glúten enriquecido com a microalga Spirulina platensis. Brazilian Journal of Food Technology, Campinas, v. 14, n. 4, p. 308-316, 2011. http://dx.doi.org/10.4260/BJFT2011140400037.

GALLAGHER, E.; GORMLEY, T. R.; ARENDT, E. K. Recent advances in the formulation of gluten-free cereal-based products. Trends in Food Science \& Technology, Cambridge, v. 15, n. 3-4, p. 143-152, 2004. http://dx.doi.org/10.1016/j.tifs.2003.09.012.

GOMES, M. C.; LOBATO, L. P.; BENASSI, M. T.; SOARES JÚNIOR, M. S. Aplicação de farelo de arroz torrado em barras de cereal. Ciência e Tecnologia de Alimentos, Campinas, v. 32, n. 4, p. 718-724, 2012.

HERA, E.; MARTINEZ, M.; GOMEZ, M. Influence of flour particle size on quality of gluten-free rice bread. LWT - Food Science and Technology, Campinas, v. 54, p. 199-206, 2013. 
Inclusão de fibra alimentar em pães isentos de glúten

Saueressig, A. L. C. et al.

HORWITZ, W. (Ed.). Official methods of analysis of the Association of Official Analytical Chemists. 17th ed. Gaithersburg: AOAC, 2000.

KOTZE, L. M. S. Doença celíaca. Jornal Brasileiro de Gastroenterologia, Rio de Janeiro, v. 6, n. 1, p. 23-24, 2006.

LACERDA, D. B. C. L.; SOARES JÚNIOR, M. S.; BASSINELO, P. Z.; CASTRO, M. V. L.; SILVA-LOBO, V. L.; CAMPOS, M. R. H.; SIQUEIRA, B. S. Qualidade de farelos de arroz cru, extrusado e parboilizado. Pesquisa Agropecuária Tropical, Goiânia, v. 20, n. 4, p. 521-530, 2010. http://dx.doi.org/10.1590/S198340632010000400004.

LACERDA, D. B. C. L.; SOARES JÚNIOR, M. S.; BASSINELO, P. Z.; SIQUEIRA, B. S.; KOAKUZU, S. N. Qualidade de biscoitos elaborados com farelo de arroz extrusado em substituição à farinha de trigo e fécula de mandioca. Archivos Latinoamericanos de Nutricion, Goiânia, v. 59, n. 2, p. 199-205, 2009.

ORMENESE, R. C. S. C.; CHANG, K. Massas alimentícias de arroz: uma revisão. Boletim do Centro de Pesquisa de Processamento de Alimentos, Curitiba, v. 20, n. 2, p. 175-190, 2002.
SILVA, R. C. O.; SILVA, K. M. C.; LIMA, F. R. B.; SILVA, C. G. M. Fibras: uma escolha saudável em benefício da saúde. In: JORNADA DE ENSINO, PESQUISA E EXTENSÃO DA UFRPE JEPEX, 9., 2009, Recife. Anais... Recife: Editora Universitária da UFRPE, 2012. Disponível em: <http://www.eventosufrpe.com.br/ jepex2009/cd/resumos/R0363-1.pdf>. Acesso em: 21 jun. 2014.

SOARES JÚNIOR, M. S.; BASSINELO, P. Z.; CALIARI, M.; GEBIN, P. F. C.; JUNQUEIRA, T. L.; GOMES, V. A.; LACERDA, D. B. C. L. Qualidade de pães com farelo de arroz torrado. Ciência e Tecnologia de Alimentos, Campinas, v. 29, n. 3, p. 636-641, 2009. http://dx.doi.org/10.1590/S0101-20612009000300028.

TORRES, G. A. M.; SIMONI, A.; GAMIM, E.; TOMAZIN, T. Proteínas de reserva do trigo: gluteninas. Brasília: Empresa Brasileira de Pesquisa Agropecuária, 2009. 6 p.

WRONKOWSKA, M.; TROSZYNSKA, A.; SORAL-SMIENTANA, M.; WOLEJSZO, A. Effects of buckwheat flour (Fagopyrum esculentum Moench) on the quality of gluten-free bread. Polish Journal of Food and Nutrition Sciences, Olsztyn, v. 58, n. 2, p. 211-216, 2008. 